\title{
TALES OF A STITCHED ANUS: \\ FICTIONS, ANALYTICS, AND PERSONHOOD IN KILIMANJARO.
}

Awarded the Curl Essay Prize 2017

Forthcoming 2019 in the Journal of the Royal Anthropological Institute 25 (1)

\author{
Knut Christian Myhre \\ University of Oslo
}

\begin{abstract}
This article revisits the fiction explored by Sally Falk Moore more than 40 years ago that initiation among the Chagga-speaking people of Tanzania's Kilimanjaro Region involved men having their anuses plugged and stitched to ensure complete digestion. It combines historical sources and contemporary fieldwork material on which it deploys an anthropological analytic adopted from Marilyn Strathern's account of the partible person of Melanesia. The move makes room for the Chagga concept of horu and investigates how this life-force is converted and conveyed by means of different parts of the body, which emerge as both effects of and means for its transfers and transformations. It renders the person a composite of social relations that are objectified in his or her body, and constitute persons as husbands and wives, and male and female. Gender categories and positions are thus modes of being that emerge as effects of particular relations. These also involve bodily alterations, like the stitched anus, that channel horu in specific forms in certain directions for particular purposes. The result is not a partible person, but a vectorial person that is a conduit of lifeforce.
\end{abstract}

Now I am ready to tell how bodies are changed

Into other bodies.

Ted Hughes, Tales from Ovid. 
Some forty years ago, Sally Falk Moore (1976) published an article that addressed a fiction pertaining to male initiation among the Chagga-speaking people of Tanzania's Kilimanjaro Region. The phenomenon she considered appeared in Bruno Gutmann's (1926) Das Recht der Dschagga, where the German missionary-ethnographer described how young men were secluded in the forest once they had recovered from circumcision. Young women and boys were told that the men had gone to endure a second intervention, which would plug and stitch their anuses shut to ensure they no would longer defecate, but digest foods fully (Gutmann 1926:324; Moore 1976:357). In the forest, meanwhile, the initiates swore never to reveal that they were still excreting, even if it was an 'open secret' that they did so; male faeces featured in female initiation, and wives and children accepted responsibility for wind passed by their husbands and fathers (Moore 1976: 361).

Moore desired an explanation for this tale, but recognized the impossibility of recovering the origins and inventions of particular symbols and myths. The task was moreover complicated by the fact that the large-scale initiation of which the tale formed part no longer was practised. In fact, Gutmann (1926:325) claimed such seclusion last occurred in the 1850s, long before he arrived in Kilimanjaro. ${ }^{1}$ Gutmann therefore combined what he observed with the accounts of older informants, whose recollections he recorded and often reproduced verbatim to reconstruct bygone activities (Jaeschke 1966:21; Winter 1979:66). Moore meanwhile linked Gutmann's descriptions with her own fieldwork material, on which she deployed the anthropological analytic of dual symbolic classification. Exploring aspects of production, reproduction, and consumption, along with initiation and other rituals, she traced the contrasting pair of 'closed' and 'open' across a range of domains, and revealed how this duality imbricates with oppositions between male/female and life/death, which in her view proved more basic than that of right/left (Moore 1976:367). In classic anthropological fashion, she located the tale of the stitched anus in relation to other aspects of 'Chagga life and thought', and made a conceptual contribution that shifted the ground for symbolic classification. Thus, Moore (1976:357-358) held, 'The mysterious notion of anal stitching can be shown to be a logical part of a larger system of related ideas'. Her account formed part of an exploration of the value and validity of 
structuralist ideas for ethnography from eastern and southern Africa (Beattie 1976; Beidelman 1961; de Heusch 1986; Kuper 1982; Needham 1960; 1967; 1976, Rigby 1966). Its shift from handedness to gender proved crucial for subsequent semiotic approaches that explore the symbolic character and role of the human body and its capacities (Beidelman 1986; 1997; Broch-Due 1993; Comaroff 1985; Feierman 1990; Herbert 1993; H.L. Moore 1986; Taylor 1992; Weiss 1996), which in turn occasioned concerns for practical and material combinations of complementary gendered forces and elements (Geissler and Prince 2010; Sanders 2008).

Large-scale initiation is indeed long gone, and Kilimanjaro has undergone pervasive changes due to colonial rule, missionization, and the introduction of coffee cash-cropping and education (Hasu 1999; Moore 1986; Pietilä 2007; Setel 1999; Stambach 2000). Nevertheless, my friend Herman and his older brother Nico told me during fieldwork in Rombo District on the eastern slopes of Kilimanjaro that their late father claimed not to defecate. ${ }^{2}$ Just as Gutmann (1926:324) described eighty years before, they said their father never visited the homestead's latrine. Until his death in the 1980s, he instead asked their mother for the iron-shovel shumbwa when the need arose. They snickered and recalled how their father proclaimed he would go uproot banana-tree stumps, when everyone knew he went to excrete in the homestead's garden. They clearly knew the truth regarding their father's bodily functions, but said that those of his generation steadfastly held that defecation was for women (wafele) and children (wana) - not for men (wasoro).

The incident reveals that the tale of the stitched anus was not wholly reliant on large-scale initiation, but pertains to phenomena that persist in the present. In this article, I therefore revisit this tale to consider again the significance of the stitched anus. I moreover follow Moore and combine my own fieldwork material with Gutmann's descriptions. As a missionary, Gutmann was obviously an agent of change in Kilimanjaro, and his attempt to reconstruct a precolonial past can be discounted. His mode of work nonetheless means that vernacular voices inflect his texts, which accordingly abound in Chagga concepts and statements. His writings therefore constitute unique sources for considering 
the longevity and change of certain ideas in the area. To explore these ideas, I too deploy an analytic that I adopt from Marilyn Strathern's (1988) account of the partible person of Melanesia. Strathern's (1988:7) notion rests on a contrast between gift and commodity that she employs as a metaphorical base for apprehending and comparing different symbolic systems. Following Gregory (1982:41), Strathern (1988:134) holds that a gift economy is one where people and things assume the social form of persons, while a commodity economy is one where they assume the form of objects. As persons, both people and things reproduce in a gift economy, where they emerge as objectifications of the exchange relations that bring them into being. Such relations activate persons and enable their reproduction, but this requires that they assume a form of incompleteness that is framed in terms of gender (Strathern 1988:185). Androgynous figures that detach and transact gendered parts to conjoin with others hence recur throughout Melanesia, where Strathern traces them across regions, activities, and domains held distinct by anthropologists.

It might seem odd to engage Strathern to shed light on the material from Kilimanjaro. However, there are reasons to surmise that some of her ideas emerge from an engagement with Africanist anthropology (Myhre 1913b). Moreover, the person that is rendered incomplete to enter into relations with others is suggestive of Gutmann's (1932:7) claim that initiation was a process of withdrawal or removal (Entziehung). This began with the piercing of the child's ears and proceeded through extraction of its lower incisors to culminate in circumcision and initiation shortly before marriage. Initiation too is a concern for Strathern (1988:208ff), who moreover explores transfers of milk, blood, and semen that also feature in Moore's (1976:365) ethnography. Hirsch (2014:47) points out how the idea that persons surrender parts to afford relations with others entails that each gender anticipates the other, as well as the outcome of their relation. The perspective renders 'male' and 'female' analogous, and reveals a host of diverse phenomena as commensurate effects of interactions that regard single-sex persons. The analogy between gendered forms unsettles the assumption that men control women, which both Gutmann (1926:324) and Moore (1976:361) posited as the purpose of the men's secret. Moreover, Strathern's account of how persons oscillate 
between gendered states counters Moore's (1976:358) claim that, '...the idea that men are naturally closed and that women are naturally open lies at the bottom of the matter'. Gender categories and identities are not fixed positions that rest on '...a fact of nature that women are weaker than men in muscular strength, and are born and remain incomplete creatures insofar as the model of human completeness includes a penis' (Moore 1976:364). Instead, they are situational effects of relations that conjoin incomplete men and women, who transact objects and substances that affect their being. The man with the plugged and stitched anus evokes the partible person, but the latter recasts distinctions between male/female, complete/incomplete, and nature/culture that Moore posited. As such, it allows for an alternative account of the stitched anus that can shed new light on her oppositions, including open/closed, life/death, and right/left.

Strathern (1988:12) uses the idea that persons contain a multitude of relations to displace anthropology's antinomy between society and the individual, which also underpins symbolic classification (Strathern 1988:172). The move allows her to describe social life as though the problem of existence is not to socialize independently existing individuals, but separate persons who render, act on, and extend the relations they contain. By placing anthropology in an incomplete state, she enables its activation by the conceptions of others to describe how persons traffic objects to explore and compare the relations and capacities they contain. She retools anthropology as a comparison of analogies or relations among relations to investigate a world where relations are the object of people's concerns. She thus uses an ethnographic phenomenon as an analytic form to upturn assumptions and make room for alternative constructs. In this way, she simultaneously expands the work of anthropology and highlights its limitations to reveal analysis as a 'controlled fiction' that turns on contingent interpretive devices (Strathern 1988:6). Fictions are then not simply something those we study have and that we may expose by means of our analytics; they are equally something we deploy to arrange and activate ethnographic material that in turn may enrich our analytics. The result is an engagement that affords vernacular notions a capacity to revise and reshape our analytical vocabulary. 
Seizing on the conjecture that some of Strathern's ideas come out of Africa and drawing inspirations from experiments with them elsewhere on the continent (Lambek and Strathern 1998; Myhre 2013a; Piot 1999; Sanders 2008; Strathern 1993; Tsékénis 2015), I extend this engagement to tell another tale of the stitched anus. Specifically, I displace symbolic classification to make room for a Chagga concept with which Gutmann wrestled, yet Moore and subsequent scholars neglect. The concept in question is that of horu, which I translate as 'life-force' or 'bodily power', and that occurs in the form of different substances, foodstuffs, and objects, whose transfers and transformations engage anatomical and architectural features, and afford changes in subject positions (Myhre 2006; 2007; 2013c; 2014; 2015; 2017; 2018). Here, I expand on this to explore how life-force is converted and conveyed by means of different parts of the body, which emerge as both the effects of and means for its transfers and transformations. Like in Melanesia, this renders the person a composite of social relations that are actualized by and objectified in the body. I also investigate how these processes constitute persons as husbands and wives, and male and female. These gender categories and positions are thus effects of particular relations, but differ from those in Melanesia in that they are gradually emergent modes of being, rather than oscillating states. Furthermore, the conversions and conveyances of horu not only affect subject positions, but involve bodily alterations that direct lifeforce in specific ways. Like in the epigraph above, it is a matter of changing bodies into other bodies, which includes a stitched anus that channels horu in specific forms in certain directions for particular purposes. The result is not a partible person, but a vectorial person that converts and conveys lifeforce in different forms by means of different parts of the body for different effects. I therefore do not apply the partible person as a theoretical concept, but deploy it as a descriptive facility to afford the becoming of another person. Engaging Strathern, I 're-describe' the tale of the stitched anus to provide a controlled fiction, and enable a conceptual transfer and transformation that afford an alternative perspective on human and other forms of being (Lebner 2016).

\section{CHANNELLING BODIES}


Moore (1976:359) argued that, 'A youth acquires the social right and theoretically the physical capacity to beget children from passing through initiation'. She asked, 'What is the association between his begetting children and the fiction of the closed anus?', and answered that, 'The explicit link is actually quite simple. He must abstain from homosexual intercourse'. In Moore's view, the reason is that a man who has undergone initiation is fertile and therefore at risk of impregnation by and of other men through anal intercourse. Her claim rests on a 'tribal teaching' gathered by Gutmann (1932:31), which remarks that a man has only one orifice and lacks a birth-canal, and therefore '...has to guard himself from having his anus used like a vagina while drunk and thus dying from the offspring.$^{3}$ According to Moore, one meaning of the anal plug ngoso is therefore that the initiated man must be closed to men and couple with women in order to reproduce.

Moore was correct that the stitched anus relates to reproduction. However, she overlooked Gutmann's (1926:324-325) claim that the complete digestion the ngoso affords is foundational for manhood (womi), and that the stitched anus is considered the embodiment of all force or power (Kraft). Gutmann did not provide the vernacular for the term he translated as Kraft, but it is reasonable to assume that it concerns the notion of horu. Winter (1979:140-141) points out that Gutmann struggled to conceptualize this notion as 'life power', while his assistant Ernst Jaeschke rendered it as 'health, well-being, success, thriving'. In line with both, horu is used in present-day Rombo to mean life-force or bodily power, which is constitutive of people's health, well-being, and capacity. These are afforded by the cooling, curing, and cleansing that the cognate verb ihora and its derivate forms designate (Myhre 2007:317; 2015:101; 2018:271ff). More importantly in this regard, they are facilitated by the consumption of foodstuffs that contain and compound horu through their cooking (Myhre 2014:511). Especially significant are different kinds of 'soft food' (kelya kiholo) that combine ingredients high in horu, such as eleusine, meat, milk, fat, blood, and certain kinds of bananas. Their consistency is also crucial, as the soft foods contrast with roast meat, dishes made from dried bananas, and the stiff maize porridge ugali that involve at least some of the same 
ingredients. Accordingly, people emphasize how the semi-liquid soft foods increase the amount of blood (samu) and speed up its circulation to raise the heat (mrike) of the body.

The soft foods capacitate and render the person active and vigorous, and able to engage in different kinds of activities. These include sex and reproduction, which are conceptualized as conversions and conveyances of horu (Myhre 2007:319; 2014:516). People for instance say that men lose horu, heat, and blood in sex, which they transfer to women in the form of semen. Women thus gain life-force and increase their blood and heat in sex, but lose them in turn through menstruation and the bloodloss of childbirth. In line with such current claims, Moore (1976:365) reported that menstrual blood is 'the fountain of life', and Gutmann (1926:11) held that a young wife is venerated as a 'giver of life' (Lebensspenderin). ${ }^{4}$ Similarly, the anthropologist Otto Raum (1996:78) - who grew up in Kilimanjaro as the son of Gutmann's colleague Johannes Raum - argued that the Chagga '...hold that the embryo results from the union of the semen with the menstrual blood, which, after impregnation, is diverted into the uterus to be used in the gradual completion of the foetus'. The child is thus a composition of the parents' life-force, which it bodies forth in a particular form. Accordingly, the child's delivery depletes the mother's horu, along with its attendant blood-loss. Women are therefore confined after childbirth, and swaddled in clothes to regain heat and provided with soft foods to replenish their blood and horu.

Colonial Oberleutnant Moritz Merker (1902:12) described how confinement lasted for two months during which women were provided with fat, butter, meat, milk, and blood. In Rombo today, women are commonly confined for three months, but served foods made from the same ingredients. It is the husband who chiefly provides these foods, but Johannes Raum (1911:182) and one-time District Commissioner Charles Dundas (1924:200) claimed that agnates of both spouses contributed to them in the past. Gutmann (1926:143-144) moreover argued that the life-force (Lebenskraft) of the woman diminished when this mutual reliance declined. Similarly, people say that these foods convey horu to the child, as they increase the mother's lactation, which affords its growth and contributes to its heat 
and blood. Accordingly, Gutmann (1926:10) claimed that breastmilk is a 'fountain of life' (Lebensbrunnen), and Moore (1976:365) argued that, 'Milk is the very source of a baby's life'. Resonating current claims, the sources reveal the longue durée of horu, yet show changes in responsibilities to provide and those who contribute to the birth and growth of a child.

Sex and reproduction hence consist in multiple conversions and conveyances of horu in the form of different bodily substances. They involve a form of recursion, as horu transfers and transmutes in certain forms to enable relations and activities where it converts and conveys in further forms. These transfers and transformations moreover engage various parts of the body that channel and convert the forms horu assume. It was recognized by Gutmann (1926:659), who argued that reproductive organs are conceptualized as 'dispatchers of power' (Kraftentsender) or 'transmitters of force' (Kraftträger), where the penis and the breasts are the most efficacious. Moore (1976:365) too touched on this, as she claimed that semen is male milk that combines with female blood to form a child, whose birth occasions breastmilk. ${ }^{5}$ For her, this was proof of dual symbolic classification, where substances alternate as male or female, and life-giving or death-dealing. By contrast, the connection persists in conceptual form in today's Rombo, where mawele is used to mean both a woman's breasts and a man's testicles. The different uses of the singular term do not concern dual categories that classify and order natural substances, but enunciate how semen and breastmilk are mutual transformations that manifest horu in different forms. The substances may consequently affect each other and are secured by sexual prohibitions that channel these forms of horu from their respective body-parts for particular purposes (Myhre 2007:322).

These conversions and conveyances involve further body-parts, which differ from those one might expect and that surface in surprising contexts. As I describe elsewhere, when a man butchers an animal, he provides his father the ikamba section of the beast's breast because his father lay on his chest when he was conceived (Myhre 2013c:117). Similarly, the man gives his wife's mother the moongo section of the animal's back because she lay on her back (moongo), first to conceive and 
later give birth to his wife (Myhre 2014:515). The practice entails that the reproductive transfers and transformations of horu occur by means of the man's chest and the woman's back, which are employed to create a child and bring it into the world. People accentuate this when they recount how a woman who in the past became pregnant before the transfer of bridewealth was forced to reveal the child's father. He was then made to lie on top of her before a sharpened dracaena (isale) stick was driven through their lower backs. As she rested on her back and he lay on his chest, the two were killed as though they were making love to manifest the body-parts employed in their transgression. Since the punishment only occurred when such sex resulted in pregnancy, it underscored the role of the chest and back for reproductive relations. ${ }^{6}$ It accentuates that the child is an effect of certain relations, where parents transform and transfer horu in different forms through various body-parts. The child consequently contains both the chest and back that its parents employed to bring it into existence, and thus personifies and embodies the relations that afford its existence and compose its being.

However, the woman's use of her back extends beyond conception and childbirth to also involve nurture and care. A further reason why a man owes his wife's mother the moongo meat is namely that she carried her daughter on her moongo when she was an infant. Gutmann (1926:311) touched on this, when he described how one term used for infants was matšovila or 'the swung ones' (die Geschwungenen). Gutmann claimed this concerned a playful practice of lifting the child and swinging it over the shoulder, but in my view it may also regard how mothers carry children on their backs, where they swing along with her activities. ${ }^{7}$ In this regard, it is also significant that women spend confinement in bed, where they rest on their backs with their babies on the breast. The back thus also features when the onus is on the woman's recovery from birth and nurture of her child. The back is hence central for transfers of horu to and from women in different forms, as body-parts beside breasts engage in the care for and feeding of the child. 
These considerations give some sense to Gutmann's claim that the stitched anus forms the basis of manhood (womi) and is the embodiment of life-force. They show that men gain horu through consumption and that digestion is crucial for their accretion of life-force. Women meanwhile also obtain horu through sex, where they use their backs in the conversions and conveyances of life-force. Accordingly, men acquire the ngoso in initiation, while women obtain their backs through the bridewealth prestations that afford reproduction (Myhre 2014:516; 2018:110ff). The stitched anus enables men to fully digest horu in the form of foodstuffs and convert it to semen, which they convey to women by means of their penises and chests. In turn, the back enables women to receive horu in this form, which combines with her blood to form a child that she grows before she delivers and nurtures it by means of her back along with her breasts. The ngoso affords men the capacity to transform and channel horu by means of certain body-parts for reproductive purposes, which women receive, convert, and pass on by means of other anatomical features. Womi, which Gutmann rendered as 'manhood', accordingly appears an abstract noun derived from 'husband' - mii. Better rendered as 'husbandhood', it involves a capacity to channel horu in certain forms in particular directions by means of specific body-parts. The tale of the stitched anus therefore concerns channelling bodies in a double sense, as it regards how persons convert and convey horu by means of different body-parts to afford the becoming of further persons, who constitute life-force in another form that contains the same anatomical features. The channelling body turns on and is sustained by its capacity to receive, transform, and transfer horu in different forms by means of different bodyparts, which consequently are both the means for and effects of these generative dynamics.

\section{ENGAGING WORLD}

Merker (1902:12) claimed that no-one could enter a confined woman's house, and close watch is currently kept on who enters the house where she and her baby rest. Whenever I was invited into such a house, I was asked if I had a 'bad thing' (kindo kiwiishwa) and queried whether I am a mwahay. While the former is a euphemism for witchcraft, the latter is a person who unwittingly startles to harm something beautiful (usha) he or she encounters. Usually, this assumes the form of a new-born 
child, germinating crops, or a house under construction. Babies therefore have charcoal rubbed on their foreheads or sewn into fabric tied around their wrists, which distracts the mwahay and prevents infliction of harm. ${ }^{8}$ The significance here is that the notion of moongo is used to mean both the doorway of the house and the back or backbone of persons and animals (Myhre 2014). The usage entails that the doorway is closely guarded regarding what and who passes through it to secure the mother's use of her back in caring for her child. The movement of persons and things through one moongo is controlled to ensure the transfers of nurture by means of another moongo.

The practice reveals that the transfers and transformations of horu not only involve parts of the human body, but engage the world and most notably features of the house and homestead - kaa. The point is broadened by the soft foods that the confined woman keeps beside her bed, and that result from productive practices in and around the kaa. In the past century, these have undergone dramatic changes due to population growth and coffee cash-cropping that occasioned or intensified land-shortages (Moore 1986:110; Setel 1999:44). Occurring earlier elsewhere on the mountain, the changes effectuated a move in Rombo from a mode of agro-pastoralism to an intensive form of horticulture, where livestock are stall-fed the leaves and stems of banana-trees to provide manure that is used to fertilize the garden (Myhre 2007:318; 2018:31ff). ${ }^{9}$ The result is an imbrication of activities that yield the staple of bananas, along with milk, meat, blood, and butter, and assorted other crops and foodstuffs. Engaging in these activities raises the person's heat and depletes his or her horu and blood, but affords foodstuffs that replenish life-force through cooking and consumption. Production too thus forms part of the conversions and conveyances of horu, which accordingly encompass crops and livestock that body forth life-force in additional forms.

Animal digestion plays a pivotal role in this regard, as it converts fodder into manure that is spread in the garden to grow crops that feed both livestock and people. My adoptive brothers moreover discussed how the banana-trees grow taller and provide larger fruit at the place of the homestead's first latrine, where the ground is full of manure (boru). In this way, they enunciated how faeces form 
part of the same transformations, which was more evident in the past when people defecated in the garden. Herman and Nico accordingly implied that their father deployed his waste to afford more crops, when he connected excretion and banana-tree cultivation. Similarly, Moore (1976:363) argued manuring meant that people connected excrements with fertility through 'technical experience', but quickly added that they could not know the chemistry involved. Therefore, 'It was more likely something akin to what we would call a magical property that made manure a fertilizing substance'. She was on the right track, but missed how salience does not concern the property of a particular entity, but a process where foods and fodder are brought into existence through mutually entailing activities, where horu is transferred and transformed by beings of different kinds.

Along with animal and human digestion, the arm or hand (koko) plays a pivotal role in these activities and the foodstuffs they yield. ${ }^{10}$ People for instance seek a person with a 'good arm' (koko kesha) to uproot excess offshoots (ndaka) and remove stumps (matonga) from harvested banana-trees. Such pruning ensures that the remaining trees grow and produce to their full potential without an abundance of offshoots to deplete their horu. It also adjusts the content of the garden, as superfluous ndaka are replanted to redistribute or augment certain kinds of bananas. Replanting is also delegated to someone with koko kesha, as this ensures that the offshoot 'seizes' or 'sticks' (iira) to grow and provide leaves, fruits, and offshoots. Similarly, someone with koko kesha is tasked to lead a cow or goat to be covered, as the semen is then more likely to 'seize' or 'stick' (iira) and result in a calf or kid. Koko kesha hence secures growth of the garden and the livestock pen, where arms harvest and slice fodder, and sweep and spread manure. The arm thus turns leaves and stems into fodder, which animal digestion converts to manure that the koko spreads to promote the provision of foodstuffs. In turn, these combine over the hearth, where the arm employs a ladle (kilikiyo) to prepare and serve foods that replace the horu people spend through production and reproduction. The foodstuffs are hence effects of multiple relationships, where the arm converts and conveys horu to replenish life-force expended by means of different body-parts. Consequently, foodstuffs emerge from the arm as entities that constitute horu in further forms. 
In addition to food crops, the garden also contains coffee-trees that have a long yet uneven history in Kilimanjaro, and where Rombo was the last district they took hold (Myhre 2009:124). Exclusively a cash-crop, its proceeds were initially spent on durable houses, education, and medical care (Moore 1986:129; Setel 1999:61; Stambach 2000:16), but are now increasingly used to obtain foodstuffs. Eleusine frequently fails due to inadequate rainfall and land-shortage has reduced livestock, so people rely on grain and milk from markets and meat from butcher shops. ${ }^{11}$ These procured foodstuffs nevertheless combine with those grown in the homesteads and plains, and thus form part of the transfers and transformations of horu. Moreover, people delegate the pruning of coffee-trees to someone with a good arm as this ensures their growth and yield, which is picked, pulped, and prepared by hand. Pruning and preparing are furthermore subject to the sexual prohibitions that surround the handling of other plants and crops to ensure their horu is not depleted or diverted. The coffee-proceeds therefore form part of the conversions and conveyances of horu, and manifest as cash that emerges from the arm. At the same time, people pay to have their cows or goats covered and thus use money to facilitate transfers of horu in certain forms, while weak coffee-prices and growing monetary needs combine to create new markets for bananas and day-labour where people convert horu into money. These markets mean that certain bananas, which previously were shared to facilitate beer parties and ceremonial events, now acquire a different value since they can be sold. The result is that cash in some contexts appears as horu in one form, while in others it intermediates, redirects, or even restricts its transfers and transformations. The long-term involvement in the monetary economy is itself a transformational process, where horu and cash come to encompass, engage, and modify each other in dialectical ways.

These considerations mean that the arm not only expends horu, but channels life-force to actualize beings of different kinds. It makes the arm a fulcrum that engages the world in multiple ways to convert and convey horu in certain forms for the purpose of affording powerful foodstuffs. When the husband provides such foods to his confined wife, he deploys the results of production for purposes of consumption and nurture that are occasioned by reproductive engagements. It recalls the elbow 
of Melanesia (Strathern 1988:272), as the arm deploys the outcomes of one set of relationships to effectuate another that results from a third. By doing so, the husband's arm adjoins the wife's mouth to fill the breasts that feed their child, which emerged from the use of their chest and back. It reveals not only how one relationship turns into another, and how different activities entail and engage each other. More importantly, it manifests how different body-parts nest as transformations of each other, as horu moves through them in different forms to afford the becoming and constitute the being of persons, animal, and crops. Each body-part is a vernacular re-description of the relation, which concerns and constitutes different means of connection and distinction that yield different effects. It recalls Taylor's (2005:144) claim that, 'Rwandans relate to one another through various aspects of themselves and not as integrated bounded entities.' In combination, the various body-parts enable and constitute an engaging world, where beings of different kinds exist as transformations of each other that emerge from different anatomical features.

\section{SHIFTING SUBJECTS}

As the father provides foods so the mother may nurse, both parents make extended and extensive reproductive contributions that broaden the range of body-parts involved and expands the relationships that compose the child. Like in Melanesia, it entails a distinction between feeding and growing that allows the father to grow the child by way of feeding its mother (Strathern 1988:238). In Kilimanjaro, this has important effects for the persons involved, which manifest in terminologies concerning subject positions.

Gutmann (1926:310ff) claimed that an infant was called matuma for the first five-six months of its life, until the first tooth arrived and the child was named. Due to its small size, the infant was also called mkoku, which people described as moitšurya nden or 'something that fills the womb'. Gutmann argued that matšovila or swung ones was used interchangeable with matuma, but mainly by the nursemaids who swung the children over their shoulders. Its use by them implies that matšovila only featured once the mother emerged from confinement and began carrying the child on 
her back. The succession of matšovila from moitšurya nden means that the child emerged from its mother's womb and shifted onto her back during confinement. Today, this is captured by the use of moongo to mean both a person's back and the doorway of the house from which mother and child emerge from confinement (Myhre 2014:518). The different uses of the singular term enunciate how the infant emerges from one moongo to be carried on another moongo.

The infant's emergence from the womb and onto the mother's back suggests that nursing helps shift the child, and that her breasts are central for its movement from one part of her body to another. It gains support from Gutmann's (1926:312) account of the midwife's return to 'rub the tooth' (isinga heho), which finalized her work of bringing the child into the world. After applying certain leaves to the child's gum, the midwife rubbed them on the mother's breasts, while saying: 'May your womb conceive'. The act and statement manifest that the breasts shift the child and release it from the womb, so the mother may conceive again. Since this will re-engage her back in sex and childbirth, the result is that one part of her body affords the use of another for reproductive purposes. The recursive character of these processes was enunciated by the midwife, who said that she received the child's tooth, just like her mother had received the tooth of the child's father, and she would return to do so again, presumably for another child.

Gutmann (1926:316) claimed it was only once a toddler could run that it was fully released from the womb and called a 'child' (mwana). The child was hence gradually separated from its mother to become a being that moves of its own accord. Today, it manifests when a mother removes the child from her back or lap and holds its hands as it stumbles around, gradually gaining the capacity to walk. Again, the child's separation chiefly occurs by means of its mother's breasts, but these are at least partly filled by her husband, who provides the foods that replenish her horu. His arm is hence also instrumental in bringing forth the child and shifting it in relation to its mother's body. Its capacity to move moreover extends the emergence of mother and child from confinement, which continued in the past when she brought the child to announce its first tooth to the grandparents (Gutmann 
1926:312). The gradual movement and separation of the child in relation to the mother hence concurred with its emergence from the house and eventual ambulation between homesteads.

However, the child not only becomes a being that is able to move, but also one that can consume foods of other kinds. Thus, when the midwife arrived to rub the tooth, she was greeted with a bowl of soft food made from milk (Milchbrei) that was called the 'child's meal' (Gutmann 1926:312). The bowl was presented with a request that the midwife receive the child's tooth, implying that the food itself brought forth the tooth. Soft food was hence presented to afford a tooth, which in turn enabled the child to eat more solid foods, thus shifting it away from breastmilk and separating it further from its mother. Raum (1996:124) realized this, when he described, 'The nutritional devolution of the original symbiosis between mother and embryo to the quasi-parasitic stage of infancy, and the ultimate independence of the two metabolic systems'. Nevertheless, he overlooked how the arm is acute for providing foods, and how the capacity to eat extends the movement of the child by means of its parents' other body-parts.

Relationship terminology reveals that these processes not only move the child, but also shift the others involved. When a woman in Rombo relocates to her marital homestead, she is addressed as 'bride' (mwali) or 'bride of child' (mwaliamwana) until she is confined, when she is known as mfee. Accordingly, Gutmann (1926:170; 1924:134) translated mfee as 'parturient woman' (Gebärerin) and wufee as 'parturient care or provision' (Wochenpflege). Both nouns derive from the verb ifee, which Raum (1909:148) rendered as 'to give birth' (gebären) and Walther (1900:41) translated as 'to beget' (zeugen). Only mfee is used in Rombo, but the other terms deepen how the confined woman is someone who has conceived a child and given birth, and therefore receives particular care. Gutmann (1924:134) furthermore revealed that the parturient provisions stem from the banana-trees, which according to my ethnography means that the wufee emerged from the arms of the homestead's inhabitants. Moreover, the mfee's use of her back lends credence to Raum's (1996:125) claim that moongo meant 'nursing mother' and was a praise-name for a woman who had borne six or more 
children. As a person who repeatedly and intensively used her back and breasts for reproductive purposes, it moreover accords with Gutmann's (1926:170) rendition of mongo as 'sucked one' (Gesogene). By contrast, Raum (1996:125-126) argued that, '...when a woman becomes the guardian and tutor of her grandchildren, she is greeted as makitshutshu, the exhausted one, intimating that her breasts have been sucked to depletion by her children and grandchildren'. Makitshutshu resembles msheku, which is the term for female elder in Rombo, where moongo means the back that the mwali uses for sex and childbirth, and the mfee rests on while nursing, as well as the doorway through which the husband brings soft foods, and she and her child eventually emerge. Its multiple meanings reiterate the recursion, where horu transfers and transforms through bodily and structural features to facilitate activities and relations where it converts and conveys in other forms.

When the mfee emerges from confinement, she reverts to be addressed as mwali and mwaliamwana, until she has borne two or more children. She is then known as mfele, which is used to mean both 'wife' and 'woman'. Mfele derives from the intensive form of ifee to mean someone who intensively births and cares for children, and is thoroughly nurtured with soft foods. Mfele is hence someone who intensively channels horu in different forms by means of different body-parts in sex and parturition. These processes bring the infant into existence and move it to become a child, which simultaneously shifts the mother to establish her as wife and woman. Like the child, the mfele too emerges from the moongo, when she comes out of the house with her second-born child. The concept and position of mfele hence also becomes as an effect of sustained engagement in transfers and transformations of horu that occur by means of different anatomical and architectural features. The gender category and position is a gradually emergent mode of being that becomes as an effect of particular relations.

The intensive verb-form is a double prepositional construction, so mfele is also a person who gives birth both to and for someone else. The construction pertains to the naming practice, where the first-born son and daughter are named after their father's parents, while their second-born siblings 
are named for their mother's parents. As I describe elsewhere, these children return to (iuya) the homesteads from which their parents came, where they are addressed as and occasionally fill the roles of their parents' parents (Myhre 2018:124). The practice means that people reproduce those who gave birth to them, so giving birth to children is also a matter of giving birth for someone else.

The naming practice moreover gives sense to the ngoso's removal, which on Gutmann's (1926:325) account occurred when a man was gaining age. A group of men then butchered a goat and tied pieces of meat to the elder's thighs, so blood ran down his legs. While untying the meat, the men called for the elder's wife, telling her that he had removed his ngoso for the sake of their sons and that she needed to care for him. In light of my ethnography, the event reversed their relationship, as the husband's blood-loss required that the wife provide for him, just like he nurtured her after she gave birth. Gutmann only said a man removed his ngoso when he was elderly, but Moore (1976:361) claimed it occurred, 'At the close of the procreative period (which formally came to an end the moment a man had a circumcized child)'. The timing meant that the father removed his ngoso so that his circumcized son could have his anus stitched. The father hence enabled his son's transformation from a child (mwana) to a husband (mii), who is capable of converting food and conveying semen by means of his penis and chest.

If Moore is correct, the removal of the ngoso preceded the birth of the son's first child, who would be named after either its father's father or its father's mother. Gutmann (1926:220) described how the father's father, on first being shown his namesake, chewed roasted banana and spat the pulp into its mouth while saying: 'Today I seize my grandchild. I now enter elderhood with my wife. Henceforth, we will remain at home to care for the child and spit food into him. But you, young mother, will go to the fields with your husband and bring us food out of your hand. Today, I have begun to spit food into him. He is my grandchild'. The statement reveals how the birth of the child turns its father's parents into elders who will no longer farm, but instead receive food from the koko of their son and his wife, which they will expectorate into their grandchild. It lends credence to the 
idea that the ngoso's removal turns a son into a husband, who can conceive a child whose birth transforms its mother from mwali into mfee, and their parents into elders. It moreover shows how these elders cease to transform and transfer horu by means of their chest, back, genitals, and arms to instead do so by means of their mouths. As they shift subject positions, they shift horu in other forms by means of other body-parts. ${ }^{12}$

In this regard, it is significant that the ikamba section the male elder claims when his son butchers, includes a piece of the animal's digestive tract. The ikamba thus manifests both how the elder lay on his chest to conceive his son, and how he spits food into the mouth of his son's children. The meat registers both his past and present use of different body-parts, and compensates for the horu transferred by their means in different forms. Gutmann's ethnography entails that the claim rests on the removal of the ngoso, which turns the claimant's child (mwana) into a husband (mii), who can impregnate a bride (mwali). Her birth of the infant (matuma) makes her an mfee for the mii to care, and transforms his parents into elders for whom they jointly provide. On reiteration, the bride becomes a wife or woman (mfele), while the husband eventually becomes a man (msoro) on account of his success in production, reproduction, and provision. Each notion and position is a transient mode of being that becomes as an effect of particular relations, where persons transform and transfer life-force in different forms by means of different body-parts. Like the body-parts, the subject positions nest as transformations of each other, which emerge as and concern different relational effects. As persons move through these positions, they turn into and out of each other to emerge as shifting subjects in a double sense, who transfer and transform horu by means of different body-parts to move the self and others.

\section{VECTORIAL PERSONS}

The ethnography above reveals how persons in Kilimanjaro are composed of life-force, which is transformed and transferred through different activities. It resembles Strathern's account from Melanesia, as it shows how the person is an effect of multiple relations that encompass a multitude 
of beings. It also reveals a concern for the separation and combination of persons, whose genders are effects of particular relations. The similarity is underscored by Gutmann's (1926:9) claim that the right earlobe of a child belongs to its father and the left ear belongs to its mother's brother. The claim suggests that the child is a divisible composite of two parts to which these men have distinct claims, as they are tasked with piercing one ear each. However, 'left' (kumooso) and 'right' (kulo) are locative constructions that derive from the noun moo and the verb ilya, which respectively mean 'life' and 'to eat'. These notions pertain to the bridewealth prestations, where women and foodstuffs emerge from and enter into houses to enable reproduction and create life (Myhre 2018:84). In this context, the notions concern the way a woman grows and feeds her child by means of the blood in her womb and milk in her breasts and the father contributes to its growth by way of feeding its mother. As she provides horu and affords life directly the maternal side is that 'of life', while the paternal side is that 'of eating' as the father provides life-force in the form of foods for her to eat.

The woman's ability to convey life is accentuated when she gives birth and the emphasis is placed on her back, whose term - moongo - also derives from moo. It can be rendered as 'conduit of life', as moongo is also the doorway through which the bridewealth prestations arrive, and from which the bride departs to gain the back she employs in sex, birthing, and childcare. Moongo is accordingly also the marital doorway through which the husband provides the confinement foods, and from which the mother and child emerge, along with the moongo meat for the wife's mother whenever he butchers (Myhre 2014:516). Butchering brings out the animal's chyme, whose term - mooshe - also derives from moo to capture this intermediary between fodder and manure as a 'substance of life' (Myhre 2018:134). Apparently unaware of this conceptual link, Moore (1976:363) nevertheless held that, 'Manure had peaceful, cooling, fertility-causing, life-bringing in it'. ${ }^{13}$ Gutmann (1926:667) furthermore argued that moo relates to the term for the hearth-fire (modo), and means a 'vitalizing glow' or 'inner fire' that accords with the 'glowing fire in the house'. Something similar is at play in Rombo, where the hearth-fire (motcho) transforms powerful substances into foods that replenish horu and raise the heat (mrike) of the body. 
In combination, kumooso, moongo, mooshe, and motcho concern places, conduits, substances, and processes from, through, along, and by means of which horu transforms and transfers. They enunciate how life - moo - is an effect of conversions and conveyances that occur between persons, houses, animals, and crops through activities that take place in and around the homestead. The notions moreover entail and engage different body-parts that convert and convey horu in different forms. Thus, the arm cuts fodder to create chyme (mooshe) and sweep manure that yields powerful foodstuffs, which may be presented through the doorway (moongo) of a homestead of the left-hand side (kumooso) to enable reproduction that employs the back (moongo), chest, and genitals. In addition, the foodstuffs are transformed over the hearth-fire (motcho) into foods that fill the breasts and load the mouths that nurse children and spit foods into them. In each case, horu assumes a particular form based on the body-part through which it converts and conveys, but that in turn is deployed by other body-parts for further transfers and transformations. As horu converts and conveys to facilitate further transfers and transmutations, the notions and body-parts concern and involve processes where the ends and means are self-similar or intrinsic to each other (Myhre 1998). Accordingly, they share a common core in the concept of moo, which enunciates how their purpose is life and its flourishing, within and of which persons, houses, livestock, and crops come into being and exist.

On this basis, it becomes clear how the form of this person differs from that of Melanesia. These processes do not involve components that are detached and transacted in modes of exchange, but transfers and transformations of life-force that occur through different parts of the body. It does not concern a partible being, but a vectorial person that directs horu in different forms through different anatomical features for different effects. The stress on fluids recalls Taylor's (1992:9ff) account from Rwanda, but differs in the equal emphasis placed on the body-parts through which they transfer and transform. ${ }^{14}$ It rather resembles Rodima-Taylor's (2013:91) account from Kuria, where '...personhood seems predicated on facilitating an assemblage of transitory connections and relations through directing material and relationship flows'. Her claim pertains to the notion of omooyo or 'passageway' that is used for the gullet and windpipe through which food, air, and water pass to facilitate obohoro 
or life, health, and well-being (Ruel 1997:121; Rodima-Taylor 2013:80). Cognates of moo and horu, omooyo and obohoro also regard how life is an effect of material transfers and transformations that occur through specific parts of the person. They too involve a vectorial person and point towards a life-force that exists between, acts on, and refracts through beings of different kinds.

Since the vectorial person is neither partible nor divisible, decomposition and elicitation receive little emphasis in Kilimanjaro, where stress is placed on affording movements through the person. Dundas (1924:203) doubted claims that the removal of incisors was a provision against lockjaw, but admitted it enabled feeding a person by means of a straw, hence facilitating transfers of soft foods. Similarly, male and female circumcisions arguably remove fleshy bits to afford the transfer of bodily fluids out of one person and into another. At least, it gives sense to Dundas's (1924:296) claim that impregnation by an uncircumcized youth was 'the most heinous crime'. Speech and language also entwine with the transfers of horu (Myhre 2013c:127; 2015:109; 2018:137), which suggests that piercing the ears facilitates the entry of one person's voice into another. Again, these acts recall Kuria, where elders who have earned their distended earlobes act as conduits of growth through invocations and acts of 'opening' (ogotora), where words, chyme, beer, and breath are made to move along gullets and through houses (Ruel 1997:29). According to Ruel (1997:69), these acts create the conditions on which life depends, which recalls the notions that derive from moo and that facilitate the transfers and transformations of horu. However, where Kuria act on livestock, beer-pots, and houses, people in Rombo excise elements of persons. Nevertheless, both create openings through acts of removal or withdrawal that afford transfers of different kinds, which facilitate life, health, and well-being that the notions of horu, omohoro, moo, and omooyo designate. It is attenuated by the fact that each modification was accompanied by prestations of powerful foodstuffs. Thus, the mother's brother received beer before piercing his sister's son's ear (Gutmann 1926:9), and circumcision began by butchering an animal (Dundas 1924:208). As these prestations afford bodily modifications that enable the movements of horu through persons, they recall how soft foods brought forth the tooth to enable the child's consumption of such foods. In each case, life- 
force is deployed in certain forms to afford its transfers in related forms, and thus facilitate life and its flourishing.

In accordance with this, the bodily interventions centre on orifices through which horu transfers in different forms. It differs from Melanesia, where the emphasis on detachment and attachment entails a focus on the skin. Where the latter makes things appear as extrinsic to the person (Strathern 1988:204), the former allows phenomena to emerge from different parts of the body. The tale of the stitched anus is part of this, but here the stress is on stopping and diverting a movement - not affording it. Thus, the ngoso facilitates complete digestion and enables a man to convert and convey the horu of foods in further forms, either through production by means of his arm or in reproduction with his chest and penis. The latter creates new life as a combination of his semen and a woman's blood, which she diverts to grow the child (Raum 1996:86). As a corollary, the man retains horu in his stomach that he releases as semen, and the woman retains horu in her womb that she releases as a child. It is underscored as the term ndeu is used to mean both the stomach and the womb. The different uses of the singular term contravene Moore's claim that men are closed and women open, as both retain and release horu albeit in different forms and at different times by means of different body-parts. The conjunction of open/closed and release/retention evokes the Rwandan relationship between flow and blockage, but modifies their antinomy, and the value and priority of one over the other (Taylor 1992:11). Instead, their imbrications are enunciated by the conceptual connection between isibo and gusiba, which concern living bodies and their parts, as well as actions and qualities of different kinds (Taylor 1992:10). Accordingly, the stitched anus does not involve a 'fictitious faecal pregnancy' (Moore 1976:359), but both the ngoso and pregnancy concern stoppages, transfers, and transformations of life-force through different parts for different effects. Both turn on and involve bodily modifications that afford and restrict the transfers and transformations of horu, and channel life-force in specific ways for particular effects. The person is therefore stitched and pierced in different ways, and made into a being that converts and conveys horu in certain ways and forms to facilitate life and its flourishing, and shift the self and others through it. 


\section{CONCLUSION}

Displacing symbolic classification makes room for the notion of horu and reveals how the stitched anus concerns material transfers and transformations, which occur within and between beings that actualize and affect each other's existence. These beings evoke Strathern's (1988:13) Melanesian persons, as '...the plural and composite site of the relationships that produced them'. Their material transfers are moreover suggestive of gift exchange, which gains support from the fact that they involve more or less ceremonial prestations. Strathern's metaphorical base also appears to extend by my use of 'production' and 'consumption', along with earlier deployments of 'exchange' to describe these affairs (Myhre 2007; 2014). The transfers and transformations furthermore suggest analogies between persons, livestock, and crops, which are accentuated by the uses of $m r i$ to mean the veins of humans and animals, and the roots of crops and plants. However, the uses exceed analogy since the veins and roots interlock, as they convert and convey horu in different forms to manifest beings of different kinds (Myhre 2018:86). Moreover, they reveal how these transfers include involuntary movements, like the flows of blood and breastmilk, and the issue of reproductive fluids. These may be effectuated and enhanced by stimulation and consumption, but they do not easily lend themselves to a transactional model of exchange. Their involuntary character moreover means that persons do not need activation, but must be modified to channel horu in appropriate forms. Thus, ears are pierced, teeth knocked out, genitals cut, and anuses stitched to turn bodies into other bodies that can receive, retain, and release life-force in certain forms. These acts of removal or withdrawal reconfigure the person and its potentialities, as they afford and animate its ability to shape and direct horu by means of particular body-parts.

Horu is moreover a cognate of the verb ihora and its derivative forms that regard cooling, cleansing, and curing, which afford and constitute health, well-being, and capacity (Myhre 2007:317; 2015:101; 2018:285). It also relates to the adjective -holo that is used for soft food, and other notions that concern the movements of horu, such as msoro for man and horo for male goat, as well as ioru for 
stream and kjore for the water-source Gutmann (1926:332) termed a place of life. The uses underscore how the transfers and transformations of horu imbricate material movements and metamorphoses in and through the world. Their liquid and circulatory character goes beyond exchange, but accords with the idea that the stitched anus concerns efforts to channel life-force in certain ways for specific effects. Together with $m r i$ and the terms that derive from moo, they reveal how horu is not something, but regards a relational force that exists between, acts on, and refracts through beings of different kinds. In combination, mfee and mfele, and msoro and horo therefore constitute and concern how man and woman or male and female are beings through which life-force moves in different forms at different times for different effects.

Like the Melanesian conventions Strathern explores, horu and the notions with which it relates amount to a theory and practice of action and production. However, the latter differ from the former in that they require a modifying rather than an activating other. Thus, Strathern effectuates a displacement that makes room for the partible person, who detaches and transacts parts of him-or herself, while I deploy her notion to afford a vectorial person, who directs life-force in different forms through different parts of the body. The partible person is activated by Strathern's anthropology of incompleteness, but in turn modified by the ethnography of the stitched anus. Like the subjects in Rombo, the two forms of personhood are versions that nest as transformations of each other, where the one emerges from the other. It follows that Strathern's notion is not applied on my ethnography as a theoretical concept, but engaged as a descriptive facility to afford the becoming of another concept of personhood. The result is a controlled fiction of the stitched anus, and a conceptual transfer and transformation. In turn, it entails that its tale is not a fiction to be exposed by our analytics, but a conceptualization of life and its flourishing that attends to the becoming, being, and abeyance of that which is by way of persons and their bodies.

\section{BIBLIOGRAPHY}

Beattie, J. 1976. Right, left, and the Banyoro. Africa 48, 217-235. 
Beidelman, T.O. 1961. Right and left hand among the Kaguru: a note on symbolic classification. Africa $31,250-257$

Beidelman, T.O. 1986. Moral imagination in Kaguru modes of thought. Bloomington: Indiana University Press.

Beidelman, T.O. 1997. The cool knife: imagery of gender, sexuality, and moral education in Kaguru initiation ritual. Washington: Smithsonian Institution Press.

Broch-Due, V. 1993. Making meaning out of matter: perceptions of sex, gender and bodies among the Turkana. In Carved flesh/cast selves: gendered symbols and social practices (eds.) V. Broch-Due, I. Rudie and T. Bleie, 53-82. Oxford: Berg.

Comaroff, J. 1985. Body of power spirit of resistance: the culture and history of a South African people. Chicago: Chicago University Press.

de Heusch, L. [1972] 1982. The drunken king: or the origin of the state. Bloomington: Indiana University Press.

Dundas, C. 1924. Kilimanjaro and its people: a history of the WaChagga, their laws, customs and legends, together with some account of the highest mountain in Africa. London: H. F. \& G. Witherby. Feierman, S. 1990. Peasant intellectuals: anthropology and history in Tanzania. Madison: University of Wisconsin Press.

Geissler, P.W. and R.J. Prince 2010. The land is dying: contingency, creativity and conflict in Western Kenya. Oxford: Berghahn.

Gregory, C.A. 1982. Gifts and Commodities. London: Academic Press.

Gutmann, B. 1909. Dichten und Denken der Dschagganeger. Beiträge zur ostafrikanschen Volkskunde. Leipzig.

Gutmann, B. 1924. Die Ehrerbietung der Dschagganeger gegen ihre Nutzpflanzen und Haustiere. Archiv für die gesamte Psychologie 48, 123-146.

Gutmann, B. 1926. Das Recht der Dschagga. Arbeiten zur Entwicklungspsychologie.

München: C.H. Beck'sche Verlagsbuchhandlung.

Gutmann, B. 1932. Die Stammeslehren der Dschagga. Arbeiten zur Entwiklungspsychologie. München: C.H. Beck'sche Verlagsbuchhandlung. 
Hasu, P. 1999. Desire and death: history through ritual practice in Kilimanjaro. Helsinki: Transactions of the Finnish Anthropological Society.

Herbert, E.W. 1993. Iron, gender, and power: rituals of transformation in African societies. Bloomington: Indiana University Press.

Hirsch, E. 2014. Melanesian ethnography and the comparative project of anthropology: reflection on Strathern's analogical approach. Theory, Culture and Society 31, 39-64.

Jaeschke, E. 1966. En Leben für Afrikaner. In Afrikaner - Europäer in nächtenschaftlicher Entsprechung (ed.) B. Gutmann, 11-31. Stuttgart: Evangelisches Verlagswerk.

Kuper, A. 1982. Wives for Cattle: bridewealth and marriage in Southern Africa. London: Routledge. Lambek, M. and A. Strathern 1998. Bodies and persons: comparative perspectives from Africa and Melanesia. Cambridge: Cambridge University Press.

Lebner, A. 2016. La redescription de l'anthropologie selon Marilyn Strathern. L'Homme 218,117-150.

Merker, M. 1902. Rechtsverhältnisse und Sitten der Wadschagga. Gotha: Justus Perthes.

Moore, H.L. 1986. Space, text and gender: an anthropological study of the Marakwet of Kenya.

Cambridge: Cambridge University Press.

Moore, S.F. 1976. The secret of the men: a fiction of Chagga initiation and its relation to the logic of Chagga symbolism. Africa 46, 357-370.

Moore, S.F. 1986. Social facts and fabrications: "customary" law on Kilimanjaro, 1880-1980. Cambridge: Cambridge University Press.

Myhre, K.C. 1998. The anthropological concept of action and its problems: a 'new' approach based on Marcel Mauss and Aristotle. Journal of the Anthropological Society Oxford 29, 121-134.

Myhre, K.C. 2006. Divination and experience: explorations of a Chagga epistemology. Journal of the Royal Anthropological Institute (N.S.) 12, 313-330.

Myhre, K.C. 2007. Family resemblances, practical interrelations and material extensions: understanding sexual prohibitions, production and consumption in Kilimanjaro. Africa 77, 307-330. Myhre, K.C. 2009. Disease and disruption: Chagga witchcraft and relational fragility. In Dealing with uncertainty in contemporary African lives (eds.) L. Haram and C. Bawa Yamba, 118-140. Uppsala: Nordic Africa Institute. 
Myhre, K.C. (ed.) 2013a. Cutting and Connecting: 'Afrinesian' perspectives on networks, exchange and relationality. Social Analysis 57, 1-155.

Myhre, K.C. 2013b. Cutting and connecting: 'Afrinesian' perspectives on networks, exchange, and relationality'. Social Analysis 57, 1-24.

Myhre K.C. 2013c. Membering and dismembering: the poetry and relationality of animal bodies in Kilimanjaro. Social Analysis 57, 114-131.

Myhre, K.C. 2014. The multiple meanings of moongo: on the conceptual character of doorways and backbones in Kilimanjaro. Journal of the Royal Anthropological Institute (N.S.) 20, 505-525.

Myhre, K.C. 2015. What the beer shows: exploring ritual and ontology in Kilimanjaro. American Ethnologist 42, 97-115.

Myhre, K.C. 2017. The power of a severed arm: life, witchcraft, and Christianity in Kilimanjaro. In Pentecostalism and witchcraft in Melanesia and Africa (eds.) K. Rio, M. MacCarthy and R. Blanes, 163-187. London: Palgrave.

Myhre, K.C. 2018. Returning life: language, life force and history in Kilimanjaro. Oxford: Berghahn. Needham, R. 1960. The left hand of the Mugwe: an analytical note on the structure of Meru symbolism. Africa 30, 20-33.

Needham, R. 1967. Right and left in Nyoro symbolic classification. Africa 37, 425-452.

Needham, R. 1976. Nyoro symbolism: the ethnographic record. Africa 46, 236-246.

Pietilä, T. 2007. Gossip, markets, and gender: how dialogue constructs moral value in post-socialist Kilimanjaro. Madison: University of Wisconsin Press.

Piot, C. 1999. Remotely global: village modernity in West Africa. Chicago: University of Chicago Press.

Raum, J. 1909. Versuch einer Grammatik der Dschaggasprache (Moschi-Dialekt). Berlin: Georg Reimer.

Raum, J. 1911. Die Religion der Landschaft Moschi am Kilmandjaro. Originalaufzeichnungen von Eingeborenen. Archiv für Religionswissenschaft 14, 159-211.

Raum, O. [1940] 1996. Chagga childhood: a description of indigenous education in an East African tribe. Hamburg: Lit Verlag. 
Rigby, P. 1966. Dual symbolic classification among the Gogo of Central Tanzania. Africa 36, 1-17.

Rodima-Taylor, D. 2013. Gathering up mutual help: relational freedoms of Tanzanian market-women. Social Analysis, 57, 76-94.

Ruel, M. 1997. Belief, ritual and the securing of life: reflexive essays on a Bantu religion. Leiden: E.J. Brill.

Sanders, T. 2008. Beyond bodies: rainmaking and sense-making in Tanzania. Toronto: University of Toronto Press.

Setel, P. 1999. A plague of paradoxes: AIDS, culture, and demography in Northern Tanzania. Chicago: University of Chicago Press.

Stambach, A. 2000. Lessons from Mount Kilimanjaro: schooling, community and gender in East Africa. London: Routledge.

Strathern, M. 1988. The gender of the gift: problems with women and problems with society in Melanesia. Berkeley: University of California Press.

Strathern M. 1993. Making incomplete. In Carved flesh - cast selves: gendered symbols and social practices (eds.) V. Broch-Due, I. Rudie and T. Bleie, 41-51. Oxford: Berg.

Taylor C. 1992. Milk, honey, and money: changing concepts in Rwandan healing. Washington D.C.: Smithsonian Institution Press.

Taylor, C. 2005. Fluids and fractals in Rwanda: order and chaos. In On the order of chaos: social anthropology and the science of chaos (eds.) M. Mosko and F.H. Damon, 136-165. Oxford: Berghahn. Tsékénis, E. 2015 'Children are the food sent by god': culinary imagery and the making of persons in the Cameroon Grassfields. Journal of the Royal Anthropological Institute (N.S) 21, 330-351.

Walther, K. 1900. Beiträge zur Kenntnis des Moschi-dialekts des Ki-Chagga (Kilimanjaro, DeutschOstafrika). Zeitschrift für Afrikanische und Oceanische Sprachen 5, 33-43.

Weiss, B. 1996. The making and unmaking of the Haya lived world. Durham: Duke University Press. Widenmann, A. 1899. Die Kilimanjaro-Bevölkerung: Anthropologisches und Ethnographisches aus dem Dschaggalande. Gotha: Justus Perthes.

Winter, J.C. 1979. Bruno Gutmann 1876-1966 - a German approach to social anthropology. Oxford: Oxford University Press. 


\section{ACKNOWLEDGEMENTS}

I gratefully acknowledge financial support from the University of Oxford, Research Council of Norway, German Academic Exchange Service (DAAD), Institute for Comparative Research in Human Culture, Nordic Africa Institute, and University of Oslo, and receipt of research permits from the Tanzanian Commission for Science and Technology. I am furthermore grateful to Kathleen Jennings, Elizabeth Hallam, and JRAI's reviewers for their comments and suggestions, and to Ashley Lebner and Tone Sommerfelt for encouraging the pursuit of this argument.

${ }^{1}$ Gutmann served in at least three different parts of Kilimanjaro from 1902 until 1938.
2 Fieldwork was conducted between April 2000 and September 2001, October 2006 and February 2007, and August and November 2008, with shorter visits in October-November 1998, April 2002, April 2003, NovemberDecember 2011, and October-November 2012.

${ }^{3}$ The 'tribal teachings' (Stammeslehren) were imparted to youth at various points, where initiation was one. However, the remark Moore drew on did not occur in connection with initiation and it makes no mention of the anal plug ngoso.

${ }^{4}$ Moore (1976:365) cited Gutmann as the basis for this, but the page reference provided does not support her claim. It is conceivable that she meant the claim by Gutmann I quote here, as Lebensspenderin is rendered as 'fountain of life' in the English translation of the Human Relations Area File, on which Moore relied. I have chosen to translate this notion more accurately as 'giver of life'.

${ }^{5}$ Moore cited Gutmann as the basis for this too, but again the page reference provided does not appear to support her claim.

${ }^{6}$ Otto Raum (1996:69) described a similar practice and claimed that this was reported from four or five generations before his writing. Dundas (1924:296) provided a slightly different account, as he argued that the practice occurred when pregnancy resulted from sexual engagement between a young woman and an uncircumcized youth. He claimed the people of Kilimanjaro considered such sexual involvement 'the most heinous crime' with the exception of one area in Rombo adjacent to my field-site. However, his claim most likely rests on a misunderstanding, as premarital sex is a common occurrence even prior to circumcision, while it is pregnancy without bridewealth that is frowned upon and lamented.

${ }^{7}$ This practice is of longstanding, as revealed by its description from the late nineteenth century (Widenmann 1899:45).

${ }^{8}$ Banana blossoms (nanua) are likewise propped on sticks in planted fields and in front of half-finished houses, so the mwahay sees these before the emergent crops or buildings.

${ }^{9}$ The mode of horticulture in present-day Rombo resembles that which Gutmann (1909:110) described from western and central Kilimanjaro more than a century ago.

${ }^{10}$ Like its Swahili cognate mkono, the Chagga koko means both the arm and the hand. For the sake of brevity, I translate koko as 'arm', even though some of the practices rather involve the hand.

${ }^{11}$ There is great variation between homesteads in the number of animals they keep. However, no-one slaughters for non-ceremonial purposes anymore, like elderly informants say they used to in the past. Similarly, some families lack milk because they do not have a cow, but even those who do have a cow need to buy milk when the animal is big.

${ }^{12}$ It is accentuated by the fact that the removal of the ngoso is the end of their reproductive careers, and hence the end of conversions and conveyances of horu by means of their genitals and breasts.

${ }^{13}$ Moore (1976:366) argued with regards to the offering of chyme to the ancestors that, 'I was told that the reason for offering stomach contents was that a beast's stomach is the very essence of its life...', which she moreover linked to faeces as part of the 'life-maintaining process'.

${ }^{14}$ Taylor (1992:12) points out that he is '...placing primary emphasis on the substances that pass through points of opening and secondary emphasis on the apertures themselves', yet also reveals that 'semen' (amasohoro) derives from the verb 'to come out' (gusohora) (Taylor 1992:230). Crucially, these appear as cognates of horu. 